\title{
Экологическое состояние подземных вод Восточного рудника АО «Апатит»
}

\author{
Даувальтер В.А. ${ }^{1}$, Даувальтер М.В. ${ }^{2}$ \\ ${ }^{1}$ Институт проблем промышиленной экологии Севера КНЦ РАH, Anamumbl, vladimir@inep.ksc.ru \\ ${ }^{2}$ Геологический институт КНЦ РАН, Anamumbl, dauvalter@geoksc.apatity.ru
}

\begin{abstract}
Аннотация. С целью оценки качества подземных вод на территории разработки Коашвинского апатитнефелинового месторождения проведены многолетние мониторинговые исследования химического состава воды нескольких скважин, расположенных в зоне влияния деятельности карьера и пробуренных до водоносного верхнечетвертичного осташковского водно-ледникового горизонта грунтовых вод f, $\operatorname{lgQ} \mathrm{III}_{\text {оs }}$, имеющего тесную связь с атмосферными осадками и процессами, происходящими на земной поверхности. Выявлена четкая достоверная тенденция к понижению уровня воды в некоторых скважинах за период исследования, а также достоверное увеличение величины $\mathrm{pH}$. Во всех скважинах отмечена тенденция увеличение содержания катионов щелочных металлов $\mathrm{Na}^{+}$и $\mathrm{K}^{+}$в последние годы. Среднее содержание аммоний-иона $\mathrm{NH}_{4}^{+}$ и нитрит-иона $\mathrm{NO}_{2}{ }^{-}$в подземных водах, а также ряда микроэлементов ( $\mathrm{Al}, \mathrm{Fe}, \mathrm{Mn}, \mathrm{Cu}, \mathrm{Hg}, \mathrm{Mo}, \mathrm{F}$ ), в несколько раз превышает величину предельно допустимых концентраций вредных веществ для воды рыбохозяйственных водоемов.
\end{abstract}

Ключевые слова: апатит-нефелиновые месторождения, Хибины, качество вод, подземные воды.

\section{Ecological state of groundwaters of the Vostochny mine of JSC «Apatit»}

\author{
Dauvalter V.A. ${ }^{1}$, Dauvalter M.V. ${ }^{2}$ \\ ${ }^{1}$ Institute of North Industrial Ecology Problems KSC RAS, Apatity,vladimir@inep.ksc.ru \\ ${ }^{2}$ Geological Institute KSC RAS, Apatity,dauvalter@geoksc.apatity.ru
}

\begin{abstract}
Long-term monitoring of the chemical composition of water from several boreholes in the zone of influence of the Koashva apatite-nepheline deposit and drilled to the aquiferous Quaternary Ostashkov water and glacial horizon of groundwaters f,lgQIII ${ }_{o s}$ with a close connection to the atmospheric precipitation and processes on a terrestrial surface, are conducted to assess the quality of groundwaters. The trend of decrease in the water level in some boreholes during research, as well as validated increase in the $\mathrm{pH}$ values is revealed. The tendency of increase in the contents of cations of alkaline metals $\mathrm{Na}^{+}$and $\mathrm{K}^{+}$is noted recently in all boreholes. The average content of ammonium ion $\mathrm{NH}_{4}^{+}$and nitrite ion $\mathrm{NO}_{2}^{-}$in groundwaters, as well as a number of trace elements $(\mathrm{Al}, \mathrm{Fe}, \mathrm{Mn}, \mathrm{Cu}$, $\mathrm{Hg}, \mathrm{Mo}, \mathrm{F}$ ), several times exceeds the size of maximum permissible concentration of harmful substances for water of fishery reservoirs.
\end{abstract}

Keywords: apatite and nepheline deposits, Khibiny, water quality, underground waters.

Одним из наиболее мощных факторов антропогенного преобразования окружающей среды являются объекты горнодобывающей промышленности. Разработка месторождений полезных ископаемых приводит к ухудшению качества природных вод, в том числе и подземных, на прилегающих территориях. Изучение техногенного воздействия горнодобывающих предприятий на подземные воды выполнялось многими исследователями и их результаты обобщены в обзорных работах (Мироненко и др., 1988, 1989). Результаты этих исследований показывают, что изменения химического состава подземных вод обусловлены как поступлением загрязняющих веществ из поверхностных техногенных накопителей (пруды-отстойники, массивы отвальных пород и т.п.), так и нарушением естественного гидродинамического режима самих подземных вод. В отработанных горных пространствах происходят процессы, вследствие которых шахтные воды приобретают повышенную минерализацию и специфический химический состав. Минерализованные воды выносят на поверхность высокотоксичные элементы, являющиеся источниками загрязнения водных артерий, которые дренируют как территорию месторождений, так и прилегающие к горнорудным районам территории.

Основной целью данной работы является оценка качества подземных вод на территории разработки Коашвинского апатит-нефелинового месторождения. Химический состав подземных вод 
исследовался в период 2004-2017 гг. в наблюдательных скважинах 10м, 11м, 14м и 15м, оборудованных на водоносный верхнечетвертичный осташковский водно-ледниковый горизонт $-\mathrm{f}, \operatorname{lgQ} \mathrm{III}_{\text {os }}$. $\mathrm{B}$ пробах подземных вод ежемесячно определялись значения $\mathrm{pH}$, ионный состав $\left(\mathrm{Na}^{+}, \mathrm{K}^{+}, \mathrm{Ca}^{2+}, \mathrm{Mg}^{2+}\right.$, $\mathrm{NH}_{4}^{+}, \mathrm{F}^{-}, \mathrm{Cl}^{-}, \mathrm{HCO}_{3}^{-}, \mathrm{SO}_{4}^{2-}$ ), содержание металлов ( $\mathrm{Al}, \mathrm{Fe}, \mathrm{Mn}, \mathrm{Sr}, \mathrm{Cu}, \mathrm{Zn}, \mathrm{Ni}, \mathrm{Co}, \mathrm{Cr}, \mathrm{Cd}, \mathrm{Pb}, \mathrm{Mo}, \mathrm{Hg}$ ), выполнялись замеры уровней воды. Проведено сравнение химического состава подземных вод исследуемых скважин и родника Мончегорского района (Даувальтер, Даувальтер, 2010). Вода в роднике нейтральная с низкими для подземных вод Мурманской области значениями общей минерализации. По преобладающим ионам вода относится к гидрокарбонатному классу и кальциевой группе. Основная гидрохимическая характеристика родника Мончегорского района и исследуемых скважин представлена в табл. 1.

Таблица 1. Средние значения величины $\mathrm{pH}$, содержания главных ионов, минерализации (М) (мг/л) и ионов азотной группы (мкг/л) воды родника Мончегорского района и исследуемых скважин.

Table 1. Average values of $\mathrm{pH}$, the contents of the basic ions, mineralization (M) (mg/l) and nitrogen group ions $(\mu \mathrm{g} / \mathrm{l})$ of the spring water of the Monchegorsk District and studied boreholes.

\begin{tabular}{|l|c|c|c|c|c|c|c|c|c|c|c|c|}
\hline \multicolumn{1}{|c|}{ Скважина } & $\mathrm{pH}$ & $\mathrm{Ca}^{2+}$ & $\mathrm{Mg}^{2+}$ & $\mathrm{Na}^{+}$ & $\mathrm{K}^{+}$ & $\mathrm{HCO}_{3}^{-}$ & $\mathrm{SO}_{4}^{2-}$ & $\mathrm{Cl}^{-}$ & $\mathrm{M}$ & $\mathrm{NH}_{4}^{+}$ & $\mathrm{NO}_{2}^{-}$ & $\mathrm{NO}_{3}^{-}$ \\
\hline Родник 2 & 7.11 & 5.2 & 4.9 & 3.5 & 1.4 & 28 & 15 & 2.4 & 60.4 & н.о. & H.o. & 660 \\
\hline Скважина 10 м & 8.22 & 6.50 & 1.56 & 11.4 & 4.52 & 45.2 & 9.67 & 4.31 & 83.2 & 571 & 504 & 1167 \\
\hline Скважина 11 м & 7.53 & 4.42 & 0.69 & 19.8 & 6.63 & 60.4 & 12.2 & 2.94 & 107.1 & 867 & 515 & 903 \\
\hline Скважина 14 м & 8.51 & 6.38 & 0.95 & 21.9 & 6.42 & 61.2 & 17.9 & 4.50 & 119.3 & 1905 & 2015 & 138 \\
\hline Скважина 15 м & 8.18 & 7.00 & 1.46 & 20.5 & 7.05 & 53.3 & 25.4 & 3.70 & 118.4 & 989 & 665 & 2790 \\
\hline
\end{tabular}

Разрез четвертичных пород представлен хорошо проницаемыми песчаными и гравийногалечными ледниковыми и водно-ледниковыми отложениями с тонкими прослоями пылеватой супеси. Поэтому водоносный верхнечетвертичный осташковский водно-ледниковый горизонт грунтовых вод $f, \operatorname{lgQIII}$ ов имеет тесную связь с атмосферными осадками, и изменение уровней воды в скважинах происходит в соответствии с сезонами года и выпадением осадков. Во время снеготаяния и выпадения дождей происходит резкий подъем уровня подземных вод, а в зимнее и летнее время без осадков происходит его снижение (рис. 1). В зависимости от рельефа местности и режима подземных вод уровни воды в скважинах залегают на глубинах от 0.09 до 20.26 м от поверхности земли. Скважина 10м из всех наблюдательных скважин находится ближе к карьеру, поэтому уровень воды в этой скважине чутко реагирует на увеличение глубины карьера. Выявлена четкая достоверная тенденция к понижению уровня воды в скважине 10м за период исследования (рис. 1). В скважине 15м также наблюдается общее понижение уровня воды, но значительно менее достоверное. В скважинах 11м и 14м наблюдается незначительное недостоверное повышение уровня воды.

По условиям формирования химического состава подземные воды Мурманской области по классификации (Каменский, 1950) относятся к грунтовым водам выщелачивания, которые формируются в условиях избыточного увлажнения, характеризуются наличием хорошо промытых и проницаемых пород, высокой динамичностью вод и активным дренажем. Влияние разработки апатитнефелиновых руд сказалось в повышении величины $\mathrm{pH}$ подземных вод по сравнению с водой родника Мончегорского района (табл. 1). В воде скважины 10м происходит достоверное увеличение величины $\mathrm{pH}$ за период наблюдений (рис. 2), что связано с усилением влияния разработки месторождения и увеличением глубины карьера. Резкие снижения величины $\mathrm{pH}$ подземных вод связаны с периодами снеготаяния и выпадения атмосферных осадков, значение $\mathrm{pH}$ которых значительно ниже (Даувальтер и др., 2008). В соответствии с требованиями к составу и свойствам воды водоемов рыбохозяйственного назначения, величина $\mathrm{pH}$ не должна выходить за пределы значений 6.5-8.5. В скважине 10 м значения $\mathrm{pH}$ превышают допустимые пределы, максимальные значения величины pH больше 10 (рис. 2). Увеличение величины $\mathrm{pH}$ связано с контактированием подземных вод со щелочными породами, содержащими щелочные и щелочноземельные металлы. Наименьшее среднее значение $\mathrm{pH}$ зафиксировано в скважине 11м вследствие наиболее высокого уровня воды в ней (рис. 1), поэтому качество воды в этой скважине наиболее чутко реагирует на изменения, происходящие на поверхности земли, в первую очередь на выпадения атмосферных осадков. Но и в этой скважине 


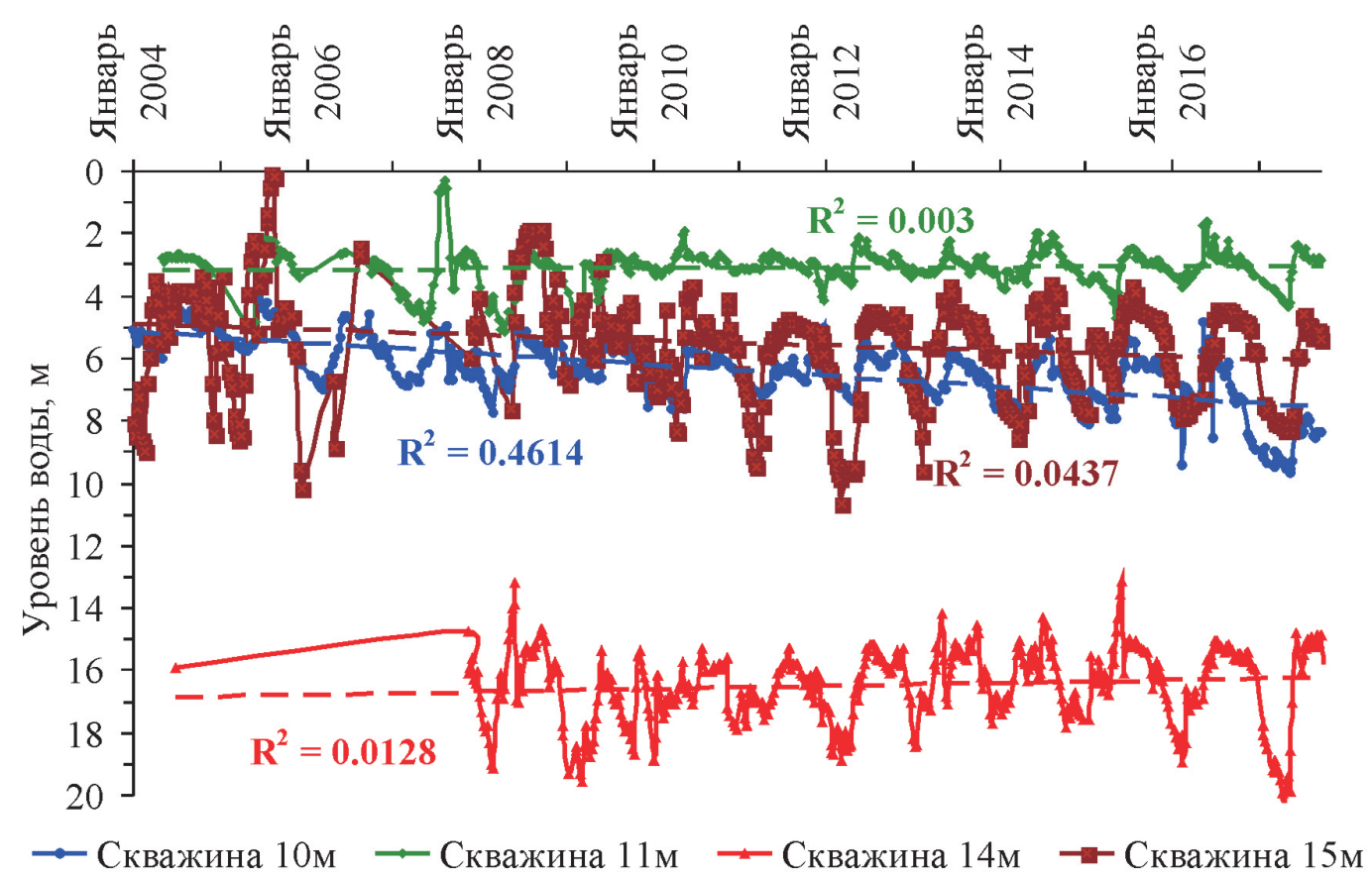

Рис. 1. Динамика уровня воды (м) в наблюдательных скважинах.

Fig. 1. Dynamics of water level (m) in observation wells.

значения $\mathrm{pH}$ увеличиваются до величин более 9 в зимнее время. Тенденция увеличения значения $\mathrm{pH}$ за период наблюдений отмечается во всех исследованных скважинах.

Подземные воды исследованных скважин по химическому составу относятся к гидрокарбонатному классу и натриевой группе (табл. 1). Особенностью химического состава подземных вод территории Коашвинского месторождения является повышенное относительное содержание катиона $\mathrm{K}^{+}$, которое сопоставимо по концентрациям с катионом $\mathrm{Ca}^{2+}$, тогда как подземные воды равнинных территорий Мурманской области, не получающие прямое загрязнение промышленных предприятий, характеризуются гидрокарбонатным классом и кальциевой группой, и катион $\mathrm{K}^{+}$, как правило, находится на последнем месте среди основных катионов (Даувальтер, Даувальтер, 2010, 2014), как в воде родника Мончегорского района (табл. 1). Во всех скважинах отмечена тенденция увеличения содержания катионов щелочных металлов $\mathrm{Na}^{+}$и $\mathrm{K}^{+}$в последние годы, что связано с выветриванием щелочных пород и попаданием его продуктов в подземные воды. Гидрокарбонат-ион является преобладающим анионом в подземных водах района Коашвинского местрождения, на втором месте стоит сульфат-ион, на третьем - хлорид-ион (табл. 1), т.е. анионный состав подземных вод имеет «классическое» распределение, характерное для незагрязненных подземных вод Мурманской области (Даувальтер, Даувальтер, 2014).

При добыче апатит-нефелиновых руд на рудниках АО «Апатит», в том числе и на Коашвинском карьере, используют азотсодержащие взрывчатые вещества, которые, попадая в подземные воды, растворяются и увеличивают содержание в них азотсодержащих ионов. Среднее содержание аммоний-иона $\mathrm{NH}_{4}^{+}$и нитрит-иона $\mathrm{NO}_{2}^{-}$значительно превышает величину предельно допустимых концентраций вредных веществ для воды рыбохозяйственных водоемов (ПДК соответственно (табл. 1). По $\mathrm{NO}_{2}^{-}$превышение ПДК ${ }_{\text {рбхз }}$ в скважине $15 \mathrm{M}$ достигает нескольких десятков раз. В последние годы в подземных водах всех исследуемых скважин отмечается рост содержания ионов азотной группы.

Вследствие разработки апатит-нефелиновых руд на Коашвинском руднике в подземных водах отмечается увеличение содержания микроэлементов, а концентрации некоторых из них превышают величины ПДК 
Таблица 2. Средние содержания микроэлементов в воде родника Мончегорского района и исследуемых скважин (мкг/л).

Table 2. The average contents of trace elements in spring water of the Monchegorsk District and studied boreholes $(\mu \mathrm{g} / \mathrm{l})$.

\begin{tabular}{|l|c|c|c|c|c|c|c|c|c|c|c|c|c|c|c|c|}
\hline \multicolumn{1}{|c|}{ Скважина } & $\mathrm{Al}$ & $\mathrm{B}$ & $\mathrm{Fe}$ & $\mathrm{Cd}$ & $\mathrm{Co}$ & $\mathrm{Mn}$ & $\mathrm{Cu}$ & $\mathrm{Mo}$ & $\mathrm{As}$ & $\mathrm{Ni}$ & $\mathrm{Hg}$ & $\mathrm{Pb}$ & $\mathrm{Sr}$ & $\mathrm{Ti}$ & $\mathrm{F}$ & $\mathrm{Zn}$ \\
\hline Родник 2 & н.о. & 37 & н.o. & 0.06 & 0.7 & 8 & 2.0 & 2.0 & 0.5 & 7.0 & н.o. & 1.0 & 10 & 4.1 & н.o. & 5.0 \\
\hline Скважина 10м & 39 & 28 & 109 & 0.05 & 0.58 & 15 & 3.5 & 14 & 1.2 & 2.3 & 0.03 & 2.26 & 77 & 5.8 & 284 & 4.3 \\
\hline Скважина 11м & 36 & 26 & 62 & 0.04 & 0.52 & 51 & 2.4 & 7.4 & 0.93 & 3.8 & 0.03 & 1.5 & 90 & 5.3 & 293 & 3.9 \\
\hline Скважина 14м & 45 & 24 & 59 & 0.07 & 0.63 & 23 & 3.0 & 14 & 0.99 & 1.4 & 0.05 & 1.2 & 112 & 6.4 & 320 & 3.2 \\
\hline Скважина 15м & 41 & 25 & 52 & 0.08 & 0.57 & 24 & 7.2 & 11 & 0.97 & 2.1 & 0.03 & 1.4 & 116 & 6.7 & 1254 & 5.8 \\
\hline ПДК & 40 & 500 & 100 & 5 & 10 & 10 & 1.0 & 1.2 & 50 & 10 & 0.01 & 100 & 104 & 60 & 50 & 10 \\
\hline
\end{tabular}

В физико-химических условиях подземных вод, в которых отмечаются высокие, до сильнощелочных (рис. 2), величины pH, Al приобретает миграционную подвижность (Никаноров, 2001), переходит из щелочных пород в раствор, что выражается в увеличении содержания этого металла, токсичного при повышенных концентрациях. Содержание $\mathrm{Al}$ превышает величину ПДК рбхз в скважинах 14м и 15м, а в других скважинах находится на границе ПДК вольно высокое в подземных водах, а в воде скважины 10м превышает величину ПДК рбхз. Значения ПДК рбхз

Особенно необходимо обратить внимание на повышенные содержания $\mathrm{Hg}$ в воде скважин. Скорее всего, поступление этого высокотоксичного и опасного для живых организмов даже в незначительных количествах металла происходит вследствие использования до последних десятилетий в капсулях-детонаторах гремучей ртути (ртутная соль фульминовой (гремучей) кислоты $\left.\mathrm{Hg}(\mathrm{CNO})_{2}\right)$ при проведении горновзрывных работ при разработке апатит-нефелиновых месторождений. В вертикальном распределении $\mathrm{Hg}$ в донных отложениях станций оз. Имандра, близко расположенных к акватории поступления стоков разработки апатит-нефелиновых месторождений, отмечаются содержания этого опасного металла в десятки раз больше фонового содержания (Dauvalter, Kashulin, 2018).

Молибденит $\mathrm{MoS}_{2}$ распространен в Хибинском горном массиве достаточно широко (Сулименко и др., 2017). Условия нахождения молибденита детально охарактеризованы А.Н. Лабунцовым, которым в 1927 г. было открыто молибденитовое месторождение Тахтарвумчорр. В пегматитах из апатит-нефелиновых пород и мельтейгит-уртитов на месторождениях Расвумчорр и Кукисвумчорр минерал присутствует в незначительных количествах. В природных водах, приуроченных к району разработки месторождения апатит-нефелиновых руд в районе Хибинского горного массива, обнаружено присутствие Мо в количествах, значительно превышающих ПДК рбхз

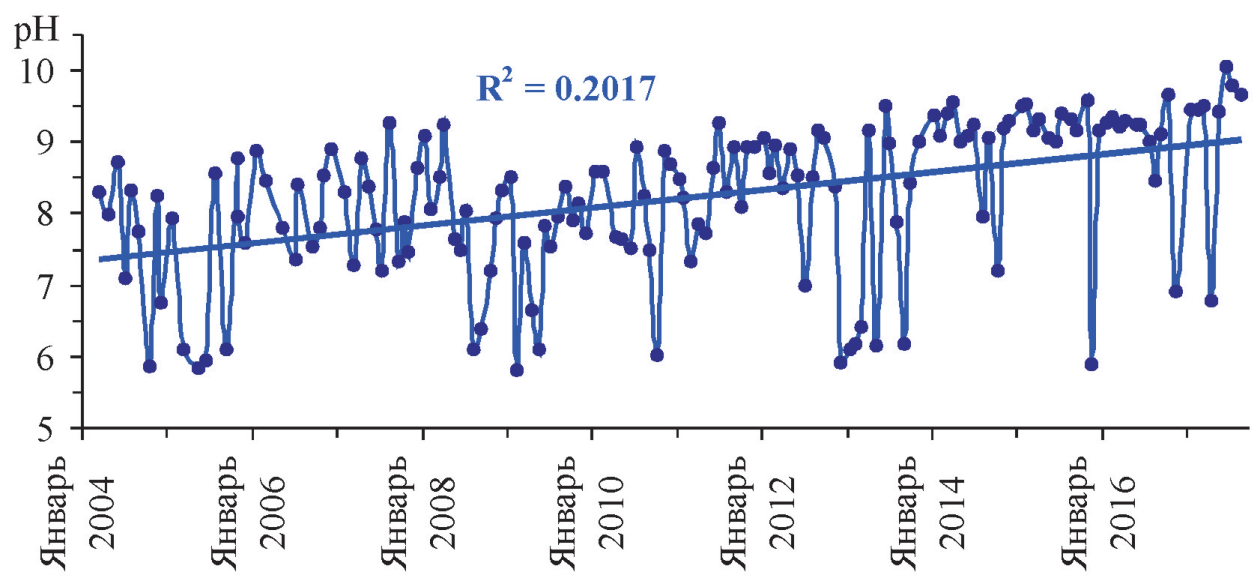

Рис. 2. Динамика величины $\mathrm{pH}$ воды в скважине 10 м.

Fig. 2. Dynamics of the $\mathrm{pH}$ value of water in a well $10 \mathrm{~m}$. 
др., 2017; Кашулин и др., 2008). В подземных водах Коашвинского карьера среднее содержание Мо в исследуемых скважинах также превышает ПДК рохз от 6 до 12 раз (табл. 2).

Главным рудным минералом Коашвинского месторождения является фторапатит $\left(\mathrm{Ca}_{5}\left(\mathrm{PO}_{4}\right)_{3} \mathrm{~F}\right)$, который при выветривании поставляет в природные воды, в том числе и подземные, F в повышенных концентрациях. В природных водах территорий, подверженных влиянию разработки апатитнефелиновых месторождений, отмечены повышенные содержания F (Кашулин и др., 2008). Не являются исключением также и подземные воды Коашвинского карьера, где среднее содержание $\mathrm{F}$ в воде скважин превышает ПДК рбхз от 6 до 21 раза (табл. 2).

Таким образом, в результате проведения многолетних мониторинговых исследований химического состава и условий залегания подземных вод на территории разработки Коашвинского апатит-нефелинового месторождения выявлена четкая достоверная тенденция к понижению уровня воды в некоторых скважинах за период исследования, а также достоверное увеличение величины $\mathrm{pH}$. Во всех скважинах отмечена тенденция увеличение содержания катионов щелочных металлов $\mathrm{Na}^{+}$и $\mathrm{K}^{+}$в последние годы. Среднее содержание аммоний-иона $\mathrm{NH}_{4}^{+}$и нитрит-иона $\mathrm{NO}_{2}^{-}$в подземных водах, а также ряда микроэлементов ( $\mathrm{Al}, \mathrm{Fe}, \mathrm{Mn}, \mathrm{Cu}, \mathrm{Hg}, \mathrm{Mo}, \mathrm{F})$, в несколько раз превышает величину ПДК

Работа выполнена в рамках темы НИР №0226-2019-0045 и частично поддержана из средств гранта РФФИ (18-05-60125).

\section{Литература}

1. Даувальтер В.А., Даувальтер М.В., Салтан Н.В., Семенов Е.Н. Химический состав атмосферных выпадений в зоне влияния комбината «Североникель» // Геохимия. 2008. № 10. С. 1131-1136.

2. Даувальтер В.А., Даувальтер М.В. Состояние подземных вод Мончегорского района // Вестник Кольского научного центра РАН. 2010. № 3. С. 26-33.

3. Даувальтер В.А., Даувальтер М.В. Геоэкологическая оценка состояния природных вод в зоне влияния комбината «Североникель». Мурманск: Изд-во МГТУ. 2014. 216 с.

4. Каменский Г.Н. Зональность грунтовых вод и почвенно-географические зоны. Тр. Лабор. гидрогеол. пробл. им. Ф.П. Саваренского АН СССР. 1950. Т. VI.

5. Кашулин Н.А., Денисов Д.Б., Сандимиров С.С., Даувальтер В.А., Кашулина Т.Г., Малиновский Д.Н., Вандыш О.И., Ильяшук Б.П., Кудрявцева Л.П. Антропогенные изменения водных систем Хибинского горного массива (Мурманская область). В 2 т. Апатиты: Изд-во КНЦ РАН. 2008. Т. 1. 250 с., Т. 2. 282 с.

6. Мироненко В.А., Мольский Е.В., Румынин В.Г. Изучение загрязнения подземных вод в горнодобывающих районах. Л.: Недра. 1988. 279 с.

7. Мироненко В.А., Мольский Е.В., Румынин В.Г. Горнопромышленная гидрогеология. М.: Недра. 1989. $287 \mathrm{c}$.

8. Никаноров А.М. Гидрохимия. СПб.: Гидрометеиздат. 2001. 444 с.

9. Сулименко Л.П., Кошкина Л.Б., Мингалева Т.А., Светлов А.В., Некипелов Д.А., Макаров Д.В., Маслобоев В.А. Молибден в зоне гипергенеза Хибинского горного массива. Мурманск: Изд-во МГТУ. 2017. 148 с.

10. Dauvalter V.A., Kashulin N.A. Mercury pollution of Lake Imandra sediments, Murmansk Region, Russia // International Journal of Environmental Research. 2018. V. 12. No. 6. P. 939-953. 